\title{
Growth and effect of Neisseria gonorrhoeae in organ cultures
}

\author{
F. E. CARNEY *, Jr., AND D. TAYLOR-ROBINSON \\ Division of Communicable Diseases, M.R.C. Clinical Research Centre, Watford Road, Harrow, Middlesex HA1 $3 U \mathcal{F}$
}

Neisseria gonorrhoeae is highly host-specific. Apart from the successful experimental infection of chimpanzees (Lucas, Chandler, Martin and Schmale, 1971) and infection of subcutaneous foreign bodies implanted in small laboratory animals (Arko, 1972), it has not been possible to infect or produce disease in species other than man. This almost total inability to infect laboratory animals has hampered studies on the mechanism of pathogenicity. We considered that the use of organ cultures, in which the relationships between tissues remain essentially undisturbed, would provide an alternative approach to studying the interaction between host cell and micro-organism. The motility of cilia on ciliated epithelial surfaces provides an index of cell viability and loss of ciliary activity due to the effect of an organism can be easily assessed. We have, therefore, inoculated Fallopian tube organ cultures with $N$. gonorrhoeae, a bacterium known to be responsible for some cases of acute salpingitis. In addition, we have inoculated the same bacterium into organ cultures of another ciliated epithelial membrane, namely the trachea. In this case, tissue was derived not only from human but also from other mammalian and avian sources. The cultures were examined for growth of the organisms and for damage caused by them.

\section{Material and methods}

\section{NEISSERIA GONORRHOEAE}

A strain sensitive to penicillin and streptomycin, obtained from the N.T.C.C. (Colindale, London), was used in the first experiment. Subsequently, a strain sensitive to penicillin (M.I.C. $<0.1 \mathrm{unit} / \mathrm{ml}$.) but resistant to streptomycin, obtained from Dr. P. T. Wormald (Public Health Laboratory, Salisbury), was used. This strain was of colonial type IV.

Received for publication January 29, 1973

*Visiting worker from Department of Obstetrics and Gynecology, Shands Teaching Hospital, Gainsville, Florida 32601, U.S.A.
MEDIA

Neisseria gonorrhoeae

Organisms were grown either in brain-heart infusion (Difco) with 20 per cent. heat-inactivated horse serum, or in medium 199 with 10 per cent. heat-inactivated foetal calf serum. To these media were added 100 units streptomycin $/ \mathrm{ml}$. and $0.05 \mathrm{M}$ HEPES buffer, the $\mathrm{pH}$ being adjusted to $7 \cdot 2$ with either $\mathrm{NaOH}$ or $\mathrm{NaHCO}_{3}$. Chocolate agar was used for growth on solid medium.

\section{Organ culture}

Organ cultures were maintained in Eagle's minimal essential medium containing $0.05 \mathrm{M}$ HEPES buffer, the pH being adjusted to $7 \cdot 2$ with $\mathrm{NaOH}$ or $\mathrm{NaHCO}_{3}$. Streptomycin 100 units $/ \mathrm{ml}$. and, in later experiments, nystatin 100 units $/ \mathrm{ml}$. were included in the medium. In some experiments oestradiol was added to the medium in a concentration of $0.6 \mathrm{ng} . / \mathrm{ml}$. and also $600 \mathrm{ng} . / \mathrm{ml}$.

\section{ORGAN CULTURES}

\section{Preparation}

Fallopian tube organ cultures were prepared from total or partial salpingectomy specimens. These were collected from the theatre immediately after removal and all subsequent procedures were done in a 'Microflow' laminar flow cabinet. The specimens were washed in $10 \mathrm{ml}$. of Eagle's medium containing appropriate antibiotics (see above). The end of the tube was grasped with fine forceps, the lumen identified, and the tube cut longitudinally with iris scissors. The opened tube was then cut into pieces 0.3 to $0.5 \mathrm{~cm}$. square with a scalpel, care being taken to crush the tissue as little as possible. These pieces were washed in medium and then placed singly or in pairs in $5 \mathrm{~cm}$. plastic Petri dishes on grid marks which had been scored with a scalpel. Medium ( $3 \mathrm{ml}$.) was added to each dish and the dishes were then placed in air-tight plastic boxes which were flushed with a 5 per cent. $\mathrm{CO}_{2}$-air mixture and incubated at $37^{\circ} \mathrm{C}$.

Occasionally, tissue pieces were placed singly in screw-capped tissue-culture tubes containing $1 \mathrm{ml}$. of medium and rolled at $37^{\circ} \mathrm{C}$.

All tracheal tissue, whether embryonic or adult, was prepared in the form of rings for organ culture as described previously (Cherry and Taylor-Robinson, 1970). Each 
ring was placed in a screw-capped tube containing $1 \mathrm{ml}$. of medium and incubated at $37^{\circ} \mathrm{C}$., either in a roller drum or stationary in a horizontal position.

\section{Ciliary activity}

The ciliary activity of Fallopian tube organ cultures was observed at the fringes of tissue pieces by means of an inverted microscope $(100 \times$ magnification) and transmitted light, or over the whole mucosal surface using conventional microscopy ( $40 \times$ magnification) and oblique illumination to highlight the cilia.

Ciliary activity of tracheal rings was observed using a conventional microscope $(100 \times$ magnification) with transmitted light and accurate quantitation of ciliary activity was possible (Cherry and Taylor-Robinson, 1970). However, quantitation was much more difficult with Fallopian tube tissue and cultures were assessed only for the presence or absence of activity.

\section{Histology}

Specimens were fixed in formol-saline or in Bouin's solution, processed by routine histological methods and stained with haematoxylin and eosin.

\section{TITRATION AND IDENTIFICATION OF N. GONORRHOEAE}

Medium removed from organ cultures was diluted in 10-fold steps in liquid medium and drops of each dilution were placed on chocolate agar medium (Miles and Misra, 1938). The cultures were then incubated at $37^{\circ} \mathrm{C}$. in containers containing 5 per cent. $\mathrm{CO}_{2}$ in air or in candleextinction jars. Colonies were counted after $24 \mathrm{hrs}$ and the number of organisms expressed as colony-forming units (CFU). Isolates from organ cultures were observed for typical colonial morphology and examined by Gramstain. Intermittent samples were examined for a positive oxidase reaction and for fermentation of glucose in the absence of maltose or sucrose fermentation.

\section{Results}

\section{DURATION OF ORGAN CULTURE PRESERVATION}

\section{Fallopian tube organ cultures}

Ciliary activity was used as an index of organ culture viability. No differences were noted in the initial ciliary activity of cultures prepared from Fallopian tubes removed during active menstrual, puerperal, or post-menopausal periods. The history of all Fallopian tube donors was not known, but in those cases in which it was known, loss of ciliary activity in cultures derived during each of these periods was about the same (Table I). Ciliary activity persisted in most organ cultures for a period of 14 days and in some for 1 month and occasionally longer. The addition of oestradiol in physiological or pharmacological concentrations, $0.6 \mathrm{ng} . / \mathrm{ml}$. and $600 \mathrm{ng} . / \mathrm{ml}$. respectively, did not reduce the loss of ciliary activity. Streptomycin and nystatin in the
TABLE I Survival of Fallopian tube organ cultures, as judged by ciliary activity, in relation to menstrual status

\begin{tabular}{lll}
\hline Menstrual status & $\begin{array}{l}\text { No. of Fallopian } \\
\text { tubes examined }\end{array}$ & $\begin{array}{l}\text { Duration of ciliary } \\
\text { activity (days) }\end{array}$ \\
\cline { 1 - 2 } Proliferative & 3 & $22,28,31$ \\
Secretory & 1 & 28 \\
Puerperal & 1 & 24 \\
Post-menopausal & 1 & $12^{\mathrm{s}}$ \\
\hline
\end{tabular}

aFungal contamination after this time

concentrations used did not seem to have a detrimental effect on the viability of the cultures. In the first Fallopian tube organ culture experiment, antibiotics were not incorporated in the medium and ciliary activity stopped rapidly as a result of nongonococcal bacterial contamination. In all subsequent experiments medium was used which contained streptomycin and the streptomycin-resistant strain of $N$. gonorrhoeae was studied.

\section{Tracheal organ cultures}

Chicken tracheal organ cultures usually survived for 2 weeks or longer, as described before (Cherry and Taylor-Robinson, 1970). Mammalian tracheal organ cultures, particularly those of murine origin, survived less well but usually lived for two weeks.

\section{GROWTH OF N. GONORRHOEAE IN ORGAN CULTURES}

\section{Fallopian tube organ cultures}

Bacterial multiplication was demonstrated in all of fifteen experiments, in each of which a different Fallopian tube was examined (Table II). Inoculation of cultures with as few as $10 \mathrm{CFU}$ resulted in rapid growth of the organisms, maximum numbers occurring 2 to 4 days after inoculation. The maximum number was usually $10^{7} \mathrm{CFU} / \mathrm{ml}$. of medium, but this varied from experiment to experiment with different Fallopian tubes and sometimes it was $10^{10} \mathrm{CFU} / \mathrm{ml}$. Typical growth curves of $N$. gonorrhoeae in Fallopian tube organ cultures are shown in Fig. 1.

\section{Tracheal organ cultures}

As shown in Table III, bacterial multiplication occurred in several experiments in which embryonic tissue of human and chicken origin was used. Tracheas from different embryos of the same species did not always support growth. Furthermore, growth was detected in stationary but not in rolled cultures. In a single experiment, growth was demonstrated in both rolled and stationary cultures of bovine embryo trachea, but this was not so in one experiment in which adult mouse trachea was used. The maximum number of organisms varied from experiment to 
TABLE II Growth and effect of N. gonorrhoeae in Fallopian tube organ cultures

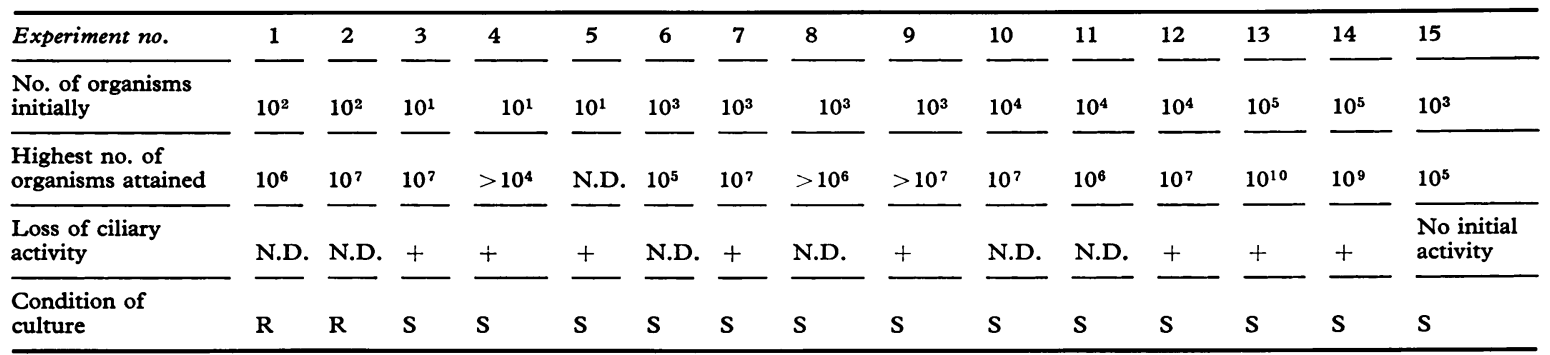

N.D. = Not determined; ciliary activity not observable in rolled cultures

$\mathrm{R} \quad=$ Rolled

$\mathrm{S}=$ Stationary

$+\quad=$ More rapid loss of ciliary activity than in uninoculated control cultures

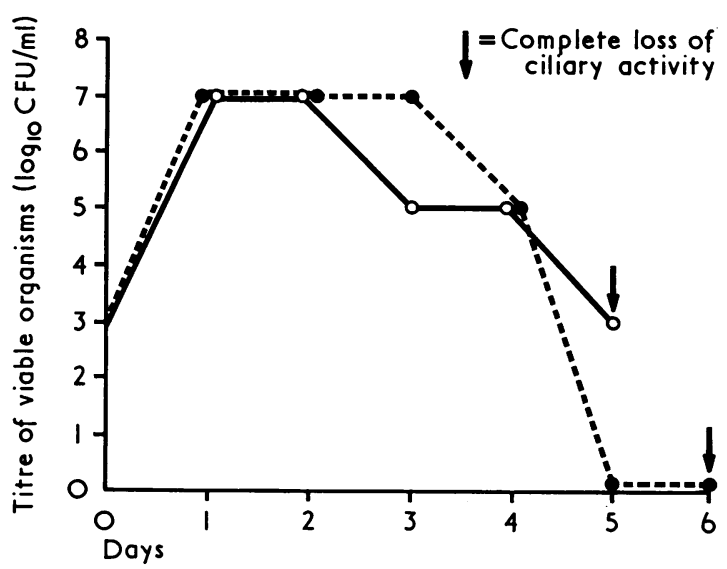

FIG. 1 Multiplication of N. gonorrhoeae in two organ cultures of a Fallopian tube

experiment and was generally higher in those in which human tissue was examined.

\section{GROWTH OF N. GONORRHOEAE IN 'CONDITIONED'} MEDIUM

Organisms $\left(3 \times 10^{2} \mathrm{CFU} / \mathrm{ml}\right.$.) died within $24 \mathrm{hrs}$ when they were incubated at $37^{\circ} \mathrm{C}$. in organ culture medium without tissue. In contrast, Fallopian tissue homogenates or medium which had been removed from uninfected cultures after contact with the tissue for 5 days (conditioned medium) supported growth. Thus, $1.2 \times 10^{2} \mathrm{CFU}$ of $N$. gonorrhoeae in such conditioned medium, and also in intact organ cultures, increased to $5 \times 10^{6} \mathrm{CFU}$ after $32 \mathrm{hrs}$ incubation at $37^{\circ} \mathrm{C}$.

\section{CILIARY ACTIVITY OF ORGAN CULTURES}

\section{Fallopian tube organ cultures}

Ciliary activity was assessed in eight experiments (Table II), in each of which a different Fallopian tube was examined. In all experiments there was a more rapid loss of activity in the cultures inoculated with $N$. gonorrhoeae than in the uninoculated cultures. The time required for total loss of activity varied from one experiment to another, loss in some being complete 2 days after inoculation, while in others this took up to 7 days. However, within a given experiment, the larger the inoculum the more rapid was the loss of ciliary activity (Fig. 2, overleaf). In contrast, activity usually persisted in uninoculated cultures for at least 14 days.

\section{Tracheal organ cultures}

In contrast to the regular and rapid loss of ciliary activity in Fallopian tube organ cultures, loss of

TABLE III Growth and effect of N. gonorrhoeae in various tracheal organ cultures

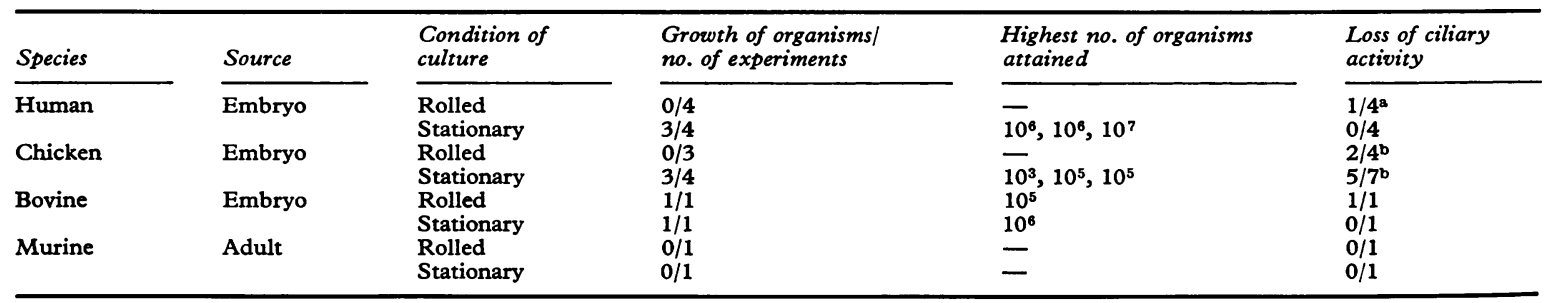

aPossible loss of ciliary activity 2 weeks after inoculation of cultures

bThere was loss of ciliary activity in some cultures that were not examined for growth of $N$. gonorrhoeae 


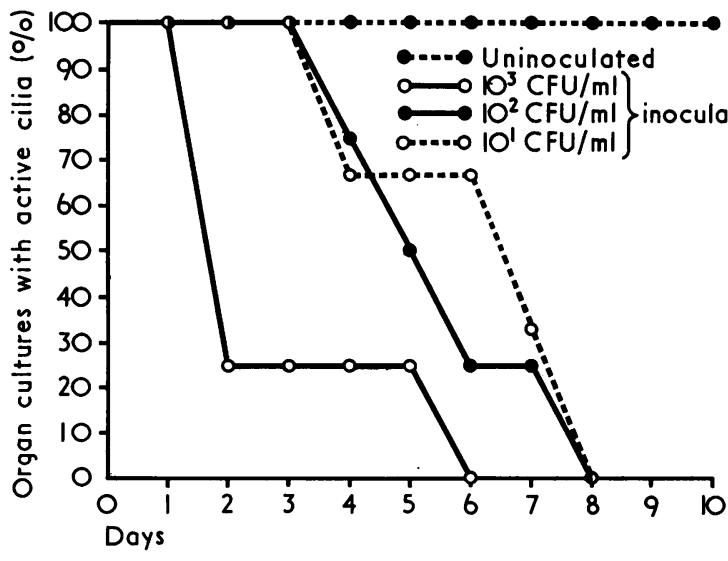

FIG. 2 Loss of ciliary activity in organ cultures of a Fallopian tube inoculated with different numbers of N. gonorrhoeae organisms

activity in tracheal organ cultures occurred infrequently (Table III). Although bacterial multiplication occurred in stationary cultures of human embryo trachea, loss of ciliary movement was not observed. In rolled cultures of the same tissue, growth did not occur, and loss of ciliary activity was not detected, except in one experiment in which activity in the inoculated cultures diminished after 2 weeks in comparison with that in uninoculated cultures. The most striking reduction in activity was seen in rolled, but not in stationary, cultures of bovine embryo trachea and in some of the experiments in which rolled and stationary cultures of chicken embryo trachea were studied. In these cultures, loss of activity occurred 3 to 7 days aiter inoculation.

\section{HISTOPATHOLOGY OF ORGAN CULTURES}

3 days after inoculation of Fallopian tube organ cultures with $N$. gonorrhoeae, a time when there were $10^{7} \mathrm{CFU} / \mathrm{ml}$. of organ culture medium, the epithelial cells were less regularly arranged than in uninfected cultures (Fig. 3). Furthermore, the thickness of the epithelial layer had diminished because of loss of cells and there was loss of cilia. The latter was probably due to loss of ciliated cells.

\section{Discussion}

Cultures of tissue cells may be infected experimentally by $N$. gonorrhoeae. Thus, Gavrilescu and Lazar (1968) grew the organisms in KB cell cultures and Kenny and Aris (1969) grew them in cultures of monkey kidney, HeLa, and human embryonic kidney

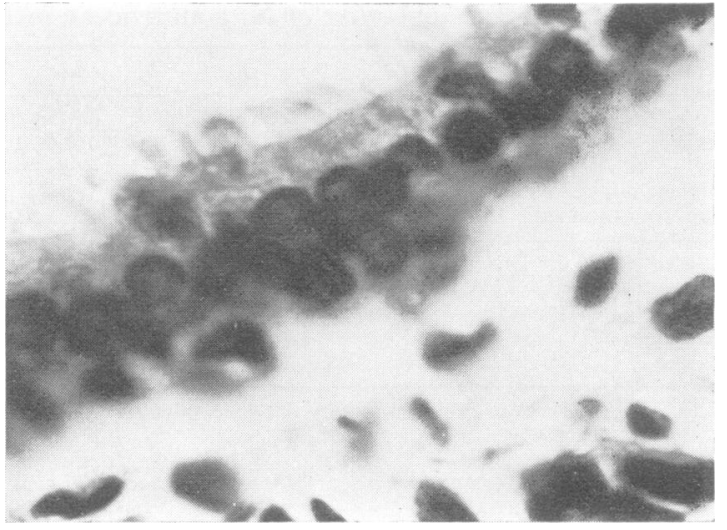

(A) Uninoculated culture after 3 days' incubation

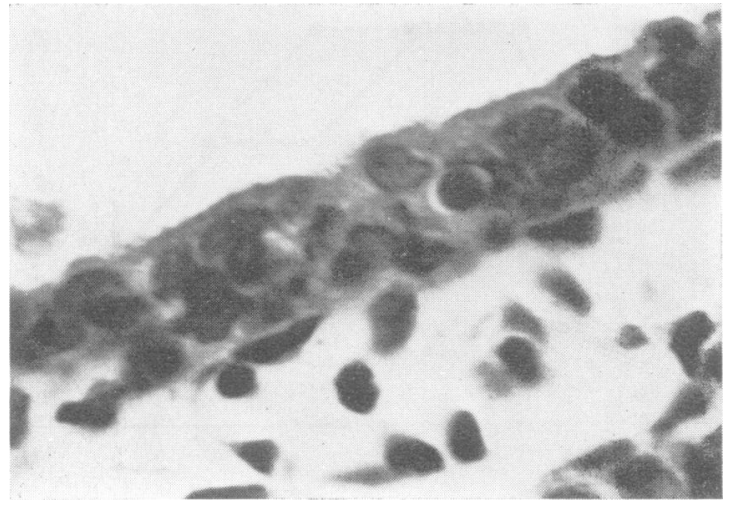

(B) Infected culture after 3 days' incubation

FIG. 3 Histopathology of Fallopian tube organ cultures infected with $\mathrm{N}$. gonorrhoeae. $\times 1,250$

cells, in all of which the cells were destroyed. Furthermore, the organisms multiplied in a continuous line of human embryo lung (L 132) cells producing a cytopathic effect (Taylor-Robinson, unpublished). Clearly, the use of tissue-cell cultures might prove of value in pathogenicity studies. However, we felt that a better approach to studying pathogenicity was to use organ cultures in which the relationships between tissues are relatively undisturbed, a situation more like that existing in vivo. Apart from the fact that the Fallopian tube is a natural end-organ for $N$. gonorrhoeae, the occurrence of tall columnar ciliated epithelium in this organ and also in the trachea is a further reason for studying such a system, since ciliary movement may be observed and used as a guide to cell viability. Tracheal tissue in organ cultures may remain viable for 3 to 5 weeks (Hoorn and Tyrrell, 1969), and we have shown that most Fallopian tube cultures also survive for a period of at least 2 weeks. The vigour of ciliary movement 
and the continued beating of the cilia seems to be hormone independent, which means that practically all Fallopian tubes are suitable for organ culture production.

Although $N$. gonorrhoeae has relatively fastidious growth requirements in vitro, it is able to multiply in the tracheal and Fallopian tube organ culture systems. In the case of mycoplasmas, host specificity is lost to some extent in organ cultures (TaylorRobinson, 1973). It was, therefore, of interest to find that $N$. gonorrhoeae multiplied in cultures of organs derived from species other than man. However, the greatest increase in the number of organisms was demonstrated in cultures of human tissue, particularly in Fallopian tube cultures, indicating some host-tissue specificity. In tracheal cultures, the organisms multiplied usually in those cultures that were stationary but not in those that were rolled. The reasons for this are not known, but a more rapid occlusion of the lumen of stationary tracheal rings by cell debris and a difference in the oxygenation of these rings and those that were rolled may be important factors. $N$. gonorrhoeae did not grow in medium to be used for maintenance of the organ cultures, but it did grow in the same medium after it had been 'conditioned' by contact with Fallopian tissue. This probably means that growth factors were released from the tissue into the medium, and it should be possible to determine their nature.

$N$. gonorrhoeae is pathogenic for the human genital tract. This is reflected in its ability rapidly to damage the Fallopian tube organ cultures. Although loss of ciliary activity occurred in tracheal cultures, most noticeably in those of chicken embryos, it was only in the Fallopian tube organ cultures that a loss of ciliary activity was consistently observed. This loss of activity was associated with histological evidence of damage, there being loss of cilia from the epithelium probably through loss of ciliated cells. The mechanism whereby this damage is brought about is unknown, but its understanding might well help to elucidate the way in which $N$. gonorrhoeae causes cellular damage in human infections. In addition, it will be of considerable interest to determine the effect on the organ cultures of $N$. gonorrhoeae colony types I and II (Kellogg, Peacock, Deacon, Brown, and Pirkle, 1963) which have been associated with disease, and to see whether organisms derived from such colonies produce even more rapid and extensive damage to the cultures than the organisms of colony type IV which we have used. It is known that organisms of colony types I and II rapidly revert to types III and IV during growth in liquid culture medium or on non-selective passage on solid medium, and it remains to be seen whether such reversion is prevented by passage in the organ culture system. It might also be possible by electron microscopy to determine the importance of ultrastructural pili (Swanson, Kraus, and Gotschlich, 1971) in cultures infected by $N$. gonorrhoeae types I and II which alone have such structures. Furthermore, the Fallopian tube model provides an opportunity to study the role of subcellular bacterial components, such as purified endotoxin (Maeland, 1969), by their addition to the system. Finally, although organ cultures are divorced from the immune mechanisms of the host, the addition of single elements of the immune cell population to the cultures offers an intriguing approach to studying the importance of these cells in immunity and pathogenicity of $N$. gonorrhoeae.

\section{Summary}

The maintenance of ciliary activity in organ cultures of Fallopian tubes removed during menstrual, puerperal, and post-menopausal periods was about the same. Ciliary activity persisted in most cultures for 2 weeks and in some for a month and occasionally longer. The addition of oestradiol to the cultures did not retard the loss of ciliary activity. $N$.gonorrhoeae multiplied in all of fifteen experiments in which Fallopian tube organ cultures were studied, and in some but not all experiments involving human, chicken, and bovine embryo tracheal organ cultures. Maximum numbers of organisms, between $10^{5}$ and $10^{10} \mathrm{CFU} / \mathrm{ml}$., were attained 2 to 4 days after inoculation of Fallopian tube cultures and lesser numbers were usually found in human, chicken, and bovine embryo tracheal cultures, indicating partial species and tissue specificity. The organisms also grew in medium after it had been 'conditioned' by prior contact with Fallopian tissue. Loss of ciliary activity was always observed 2 to 7 days after inoculation of Fallopian tube cultures and there was histological evidence of damage. In the tracheal cultures, loss of ciliary activity was seen most frequently in those of chicken origin. The organ culture system, particularly that involving Fallopian tubes, would seem to provide a useful model for studying various aspects of $N$. gonorrhoeae virulence.

\section{References}

ARKo, R. J. (1972) Science, 177, 1200

CherRy, J. D., and Taylor-Robinson, D. (1970) Appl. Microbiol., 19, 658

GavrilesCU, M., and LAzAR, M. (1968) Acta. dermosif. (Madr.), 59, 429

Hoorn, B., and TyRrell, D. A. J. (1969) Progr. med. Virol., 11, 408

Kellogg, D. S., JR., Peacock, W. L., JR., Deacon, W. E., Brown, L., and Pirkie, C. I. (1963) F. Bact., 85, 1274 
KenNy, C. P., and Aris, B. (1969) Can. F. publ. Hlth, 60, 34

Lucas, C. T., Chandler, F., Martin, J. E., and Schmale, J. D. (1971) F. Amer. med. Ass., 216, 1612

Maeland, J. A. (1969) Acta path. microbiol. scand., 76, 475

Miles, A. A., and Misra, S. S. (1938) f. Hyg. (Camb.), 38, 732

Swanson, J., Kraus, S. J., and Gotschlich, E. C. (1971) F. exp. Med., 134, 886

TAYloR-Robinson, D. (1973) 'Proc. IV Int. Symp. Aereobiol', p. 196. Oosthoek, Utrecht

Développement et action des Neisseria gonorrhoeae sur les cultures d'organes

\section{SOMMAIRE}

La persistance de l'activité ciliaire en cultures d'organes fut à peu près la même pour des trompes de Fallope prélevées pendant les périodes menstruelle, puerpérale et post-ménopausique. L'activité ciliaire persista pendant 2 semaines dans la plupart des cultures, pour quelques unes pendant un mois et, éventuellement, plus longtemps. L'addition d'oestradiol aux cultures n'a pas retardé la perte de l'activité ciliaire.
Les Neisseria gonorrhoeae se multiplièrent dans toutes les 15 expériences dans lesquelles les cultures de trompe de Fallope furent étudiées et, dans quelques unes, mais non dans toutes celles portant sur des cultures de trachée d'embryons d'homme, de poulet ou de bovins. Les nombres maximaux d'organismes, entre $10^{5}$ et $10^{10}$ unités de formation de colonies/ml, furent atteints deux à quatre jours après l'inoculation dans les cultures de trompe de Fallope et des nombres plus faibles furent généralement trouvés dans les cultures de trachée d'embryons d'homme, de poulet ou de bovins, ceci indiquant une spécificité partielle des espèces et des tissus. Les organismes se développèrent aussi dans le milieu après que celui-ci ait été "conditionné" par contact préliminaire avec du tissu fallopien. La perte de l'activité ciliaire fut toujours observée deux à sept jours après l'inoculation des cultures de trompes de Fallope et l'histologie montra des signes d'altération. Dans les cultures de trachées, la perte de l'activité ciliaire fut observée beaucoup plus fréquemment pour les trachées de poulet. Le système des cultures d'organes, en particulier lorsqu'il s'agit de trompes de Fallope, semblerait procurer un modèle utile pour étudier différents aspects de la virulence du Neisseria gonorrhoeae. 